\title{
Hand function 5 years after treatment with collagenase Clostridium histolyticum injection for Dupuytrens disease
}

Ingrid Goransson, Lars Brudin, Andra Irbe and Christina Turesson

The self-archived postprint version of this journal article is available at Linköping University Institutional Repository (DiVA):

http://urn.kb.se/resolve?urn=urn:nbn:se:liu:diva-176881

N.B.: When citing this work, cite the original publication.

Goransson, I., Brudin, L., Irbe, A., Turesson, C., (2021), Hand function 5 years after treatment with collagenase Clostridium histolyticum injection for Dupuytrens disease, Journal of Hand Surgery, European Volume, , 17531934211002383. https://doi.org/10.1177/17531934211002383

Original publication available at:

https://doi.org/10.1177/17531934211002383

Copyright: SAGE Publications

http://www.uk.sagepub.com/home.nav 
TITLE: Hand function five years after treatment with collagenase clostridium histolyticum injection for Dupuytren's disease.

Authors: Ingrid Göransson ${ }^{1}$, Lars Brudin ${ }^{2,3}$, Andra Irbe ${ }^{4}$, Christina Turesson ${ }^{5}$.

1. Department of Occupational therapy and Physiotherapy, Kalmar County Hospital, Regional Council in Kalmar County: Kalmar, Sweden.

2. Department of Clinical physiology, Regional Council in Kalmar County: Kalmar, Sweden.

3. Department of Health, Medicine and Caring Sciences, Linköping University, Linköping, Sweden.

4. Orthopaedic Clinic, Kalmar County Hospital, Regional Council in Kalmar County: Kalmar, Sweden.

5. Department of Hand Surgery, Plastic Surgery and Burns, and Department of Biomedical and Clinical Sciences, Linköping University, Linköping, Sweden.

Corresponding author: Ingrid Göransson, Rehab söder, hus 48 plan 1, Länssjukhuset, S-391 85 Kalmar+4676-8023989, 08goransson@gmail.com, ingrid.goransson@regionkalmar.se.

Keywords Dupuytrens disease, collagenase, long term follow-up, hand function, satisfaction, activities of daily living

Acknowledgements The authors would like thank to the Orthopaedic Clinic and Department of Occupational Therapy at Kalmar County Hospital and Department of Hand Surgery, Plastic Surgery and Burns, Linköping University Hospital for generous help and support during the study process. 
Declaration of conflicting interests The authors declare no potential conflicts of interest with respect to the research, authorship, and/or publication of this article.

Funding The authors received no financial support for the research, authorship, and/or publication of this article.

Ethical approval The study was approved by the Swedish Ethical Review Authority in Linköping, Sweden, Dnr 2017 / 389-31.

Informed consent Verbal informed consent was obtained from all patients before the study. 


\begin{abstract}
The aim of this study was to report hand function, disability and satisfaction, and patients' perception of functionally troublesome contractures five years after injection with collagenase clostridium histolyticum and hand therapy for Dupuytren's disease. Data from 79 patients were collected before and at three, 12 and 60 months after treatment. Hand function was significantly improved, and $70 \%$ achieved a functional range of motion in the treated hand. QuickDASH scores and range of motion were best at three months follow-up. At 60 months, mean total extension deficit was 48 degrees which was $57 \%$ of the deficit before treatment. Thirty-seven patients (47\%) had developed recurrent contractures in treated finger(s) meeting the criteria for new treatment. The threshold for functionally troublesome contractures was found to be 30-60 degrees in the finger joints. Treatment was experienced as painful, but few hand function problems occurred. Most patients would choose this treatment method again.
\end{abstract}

Level of evidence: IV

Key words: Dupuytren's disease, collagenase, long-term follow-up, hand function, satisfaction, activities of daily living. 


\section{INTRODUCTION}

Since injection with collagenase clostridium histolyticum $(\mathrm{CCH})$ was approved for treatment of Dupuytren's disease in 2011, it has become an alternative to fasciectomy and needle aponeurotomy (Zhao et al., 2016). Recurrence can occur after all treatment methods (Layton and Nanchahal, 2019) and has been defined as loss of $20^{\circ}$ of passive motion per treated joint (Kan et al. 2017). Recurrence and complication rates have been shown to be important in patients' preferences for treatment (Kan et al., 2016). Long-term outcomes (3-5 years) after $\mathrm{CCH}$ injection have shown the treatment to be more effective in metacarpophalangeal (MCP) joints, while risk of recurrence is higher in proximal interphalangeal (PIP) joints (Nordenskjöld et al., 2019; Peimer et al., 2015a). Outcomes on disability and satisfaction five years after $\mathrm{CCH}$ injection have shown improvements, especially among those treated for the MCP joints (Werlinrud et al., 2018). However, further knowledge is needed about long-term changes in hand function after $\mathrm{CCH}$ injection that may affect the ability to use the hand in daily activities. Thus, a combination of outcome measures has been proposed to best evaluate treatment results (Ball et al., 2013; Layton and Nanchahal, 2019).

The aim of this study was to report hand function, disability and satisfaction, and patients' perception of functionally troublesome contractures five years after injection with $\mathrm{CCH}$ and hand therapy for Dupuytren's disease. 


\section{METHODS}

This was a retrospective, single centre cohort study including examination on four occasions: before treatment and at three, 12- and 60-months after $\mathrm{CCH}$ injection. A quantitative method was used with physical measurements and standardized questionnaires as well as interviewbased study-specific questions. The study was approved by the Swedish Ethical Review Authority in Linköping, ref 2017 / 389-31.

\section{Patients}

The study group consisted of the first 102 patients treated with $\mathrm{CCH}$ injection at the Kalmar county hospital during 2012 - 2014. They had been followed in a structured way for one year for quality assurance purposes. Inclusion criteria for the present study were being willing to participate in the study and having had treatment with $\mathrm{CCH}$. The cases included both primary and recurrent Dupuytren's disease. Criteria used at the clinic, when the method was introduced, were a palpable cord impairing daily activities and causing an extension deficit of at least 45 degrees in an isolated finger joint (MCP or PIP joint) or more than 60 degrees as the sum of the extension deficits in the whole finger.

Exclusion criteria were treatment for the thumb or having other health problems that affected the possibility of participation, e.g. dementia. Of the 102 patients, 96 had participated in a 12month follow-up. When checking against the population register, eleven of those 96 had died, leaving 85 patients eligible for the present study. The patients were contacted by letter which was followed up by telephone with a request for participation in a five-year follow-up. As many patients were elderly, we offered to carry out the follow-up at home or at a convenient care facility. Three declined to participate, two had other health issues and one was living abroad. Seventy-nine patients accepted and gave verbal consent to participate. Of these, 56 were treated for one finger and 23 for two or three fingers. The first treatment for each patient was included in the study. Background data on the study sample is given in Table 1. 


\section{Treatment}

All $\mathrm{CCH}$ injections and extension procedures were performed by the same experienced specialist physician (AI) (level 3, Tang and Giddins, 2016), who had also assessed that criteria for treatment were met at a preparatory visit. $\mathrm{CCH}$ was given in accordance with the pharmaceutical company's safety directives. For each patient, a vial of $0.9 \mathrm{mg}$ of clostridium powder was diluted with $0.4 \mathrm{ml}$ of sterile diluent and injected into the cord. A maximum of three cords in the hand were treated at the same time. Extension of the finger(s) was performed after a mean of four days (range 2-6). Local anaesthesia with 1\% Carbocaine was used to prevent pain. Thirty-two patients experienced some degree of skin rupture after the extension procedure of which deep skin lesions $(n=8)$ were bandaged in a plaster splint for one week (Table 1). Oedema occurred after both the injection and the extension procedure which was severe in 6 cases. Ongoing treatment with anticoagulants was not paused, to avoid circulatory/blood clotting risks to the patients $(n=6)$.

After extension of the finger(s) (or removal of the plaster), an occupational therapist (OT) fitted the patient with a palmar custom-made finger extension orthosis immobilizing the wrist and part of the hand to be used day and night for $3-5$ days. Thereafter, the patients were instructed to use it at night for 3 months. Instructions were given for active finger flexion and extension at the same first visit. Hand function and fit of the orthosis was checked by the OT after one week. The participants used the orthosis for varying lengths of time (median 87, range 8 -198 days). Additional visits to the OT for follow-up were based on the patients' need (median 2, range $1-8$ visits). 


\section{Data collection}

Data from before treatment and at three- and 12-month follow-up was obtained from the patients' records. Information collected consisted of physical examination of hand function and self-reported questionnaires. The initial measurements at baseline had been performed by OTs just before treatment. The follow-up examinations and measurements at three and 12 months had been performed by OTs at the county hospital or, in some cases, by OTs at nearby hospitals. Data collection at the five-year follow-up was carried out by one of the OTs who participated in the introduction of the $\mathrm{CCH}$ treatment at the clinic.

Physical examination of hand function consisted of:

- Active range of movement of the MCP, PIP and distal interphalangeal (DIP) joints in treated fingers measured with a goniometer according to guidelines (HAKIR, 2010, 2019) at all follow-up assessments.

- Palpation and note of nodules and new cords in the hand.

- Touch sensibility in the worst finger measured at the fingertip with SemmesWeinstein's monofilaments (SWM) (Bell Krotoski, 2011) at baseline and after three and 12 months.

The questionnaires filled in at all follow-up visits consisted of:

- Swedish translation of the Quick Disabilities of the Arm, Shoulder and Hand questionnaire (QuickDASH) (Atroshi et al., 2000; Rodrigues et al., 2016). Minimal clinically important difference for the QuickDASH is $16-20$ points (Franchignoni et al., 2014).

- Problems with hand function questions taken from the survey HQ-8 in the Swedish National Quality register for Hand Surgery (HAKIR) (HAKIR, 2010, 2018) relating to pain on load, pain during motion without load, pain at rest, stiffness, weakness, 
numbness/tingling and cold sensitivity. All questions were estimated on a visual analogue scale (VAS) where $0=$ no problems and $100=$ worst possible problems.

- Diagnostic and study-specific questionnaires that included the patient's experience of treatment and physical and mental satisfaction with the result of treatment.

Satisfaction with current hand function was estimated on a 7-degree scale from very satisfied to very dissatisfied. Overall satisfaction with outcome of treatment was collected from the HAKIR survey (HAKIR, 2010, 2018) and was estimated with VAS where $0=$ very satisfied and $100=$ very dissatisfied. Ability to use the hand in daily activities was estimated on a ten-point scale where $1=$ very poor and $10=$ very good.

- Experience of pressure/touch discomfort to the palmar surface was estimated at all follow-up assessments on a 4-degree scale from "not at all" to "severe problems".

- Two open-ended questions were included at the five-year follow-up. The first question regarded difficulties in everyday life before treatment and the second about patients' opinion when the contractures became troublesome for these activities. The patients were instructed to shape their fingers into the estimated interfering position. The MCP and PIP joints angles were then measured with a goniometer.

\section{Analysis}

We calculated the total active flexion (TAF) and total active extension deficit (TAE) by adding measurement of the isolated finger joints respectively, giving the total active range of motion (AROM). Hyperextension at any joint was converted to 0 degrees. To manage multiple observations, (Altman and Bland, 1997; Bryant et al., 2006) patients were divided into two subgroups: patients with one treated finger $(n=56)$ and patients with multiple treated fingers $(n=23)$. For the patients with multiple treated fingers, we calculated a mean ROM for the MCP, PIP and DIP joints as well as for total AROM (Matthews et al., 1990). Outcomes 
were compared to a mean total arc of functional range of motion of 170 degrees (Bain et al., 2015), using the McNemar test.

Differences between subgroups were analysed using Fisher's exact test and Mann-Whitney Utest. Analyses of hand function and questionnaires were conducted on the entire group $(\mathrm{n}=$ 79). Repeated measures ANOVA with subgroups as categorical predictor was used to compare changes over time, followed by Tukey's post hoc test in case of significance. When analysing recurrence rates and satisfaction with current hand function, the results were also compared for two age groups, divided by median age $(68)$ to 68 years or less $(n=41)$ and over 68 years $(n=38)$ at treatment. Patients who had further treatment for the same finger(s) $(n=9)$ were excluded from the calculation of recurrence. 


\section{RESULTS}

\section{Multiple treatments}

During the five-year period after $\mathrm{CCH}$ injection, 17 of 79 patients had been treated with further $\mathrm{CCH}$ injection or fasciectomy, nine of them for recurrence in treated finger(s) and others for increasing contractures in another finger or in the other hand. Three had been treated for both hands. When participants were asked if they wanted to repeat treatment with $\mathrm{CCH}$ if a new contracture was to be developed, 63 (80\%) said yes. Those who answered no cited advanced age, pain/discomfort during treatment, acceptance of their hand function or desire for a long-lasting treatment. Four participants would prefer fasciectomy.

\section{Changes in range of motion}

Changes in digital range of motion up to five years after treatment are presented for individual joints and whole fingers (Figure 1, Table S1 A-C). The changes in digital extension and total active range of motion were statistically significant $(\mathrm{p}<0.001)$. Changes in finger flexion were not significant.

Among patients who did not have further treatment, 49 (70\%) exceeded a total arc of functional $\mathrm{ROM}\left(170^{\circ}\right)$ in the fingers (Table 2). Among the isolated finger joints the MCP joints ( $\mathrm{n}=99)$ were especially improved and showed slightly less deterioration of extension than the PIP joints ( $\mathrm{n}=81)$ (mean $12^{\circ}$, SD 21, and mean $14^{\circ}$, SD 18 respectively). There was significantly greater TAE $(p=0.031)$ and lower AROM $(p=0.016)$ in patients who had had previous fasciectomy in the same hand $(n=11)$ compared to those with less extension deficits who had $\mathrm{CCH}$ injection as primary treatment $(\mathrm{n}=53)$ (Table S1 A and C).

There was a non-significant tendency for lower recurrence $(p=0.08)$ in the older group (mean $22^{\circ}$, SD 31) compared to the younger one (mean $35^{\circ}$, SD 39). Overall, after five years, $47 \%$ 
(37 of 79) in the study group had redeveloped contractures in the treated finger(s) that met the inclusion criteria for new treatment (palpable cord, $45^{\circ}$ in a single joint or a total of $60^{\circ}$ in the same finger, and the finger impeding in daily activities).

\section{Hand function}

Patients rating of hand function showed moderate problems with stiffness but also mild problems with weakness and cold sensitivity before treatment (Table 3). Stiffness was reduced during the first year after treatment but had increased at the five-year follow-up. The $\mathrm{CCH}$ injection was described as painful by $65 \%$ of the patients. Over time, perceived pain in the hand decreased as well as problems with pressure/touch to the palm.

At baseline, cold sensitivity was estimated with VAS $>50 / 100$ by $38 \%(n=30$ of 79$)$ participants. At the five-year follow-up, the number had decreased to $16 \%(\mathrm{n}=13$ of 79$)$. However, four patients described new or increased problems with cold sensitivity in the treated finger after $\mathrm{CCH}$ treatment. About $70 \%$ of the participants perceived touch with 0.4 grams of pressure (reduced light touch) with SWM. Minor insignificant changes occurred between baseline and 12 months, in both a positive and negative direction.

\section{Disability and satisfaction}

Disability measured with Quick-DASH was significantly reduced $(\mathrm{p}<0.001)$ after treatment and was, for the entire group, best after three months (Table 3). The subgroup with multiple treated fingers consistently had higher scores than the group with one treated finger. The tasks in QuickDASH that were considered most difficult were opening jar lids, power-intensive leisure activities and coping with daily work or activities requiring dexterity. At five-year follow-up most were no longer employed, which reduced the demands of speed, dexterity, and ROM in the hand. 
Participants were asked to estimate satisfaction with their current hand function and the ability to use the hand in their daily activities five years after treatment (Table 4). Those who had no other treatment before the $\mathrm{CCH}$ injection and did not undergo further treatment were most satisfied with both their hand function and with their ability to use the hand in daily activities, especially those treated for one finger.

Persons with $\leq 45^{\circ}$ TAE deficit in the treated finger(s) at five-year follow-up estimated themselves more satisfied with their hand function and were able to use their hand better in daily activities than those with larger extension deficits (Table S2). Both age groups had similar results for satisfaction. Overall satisfaction with $\mathrm{CCH}$ treatment results, assessed with VAS 0 - 100, was best after three months (mean 7, SD 13), decreased at 12 months (mean 14, SD 23), and decreased further to the five-year follow-up (mean 26, SD 35).

\section{Functionally disturbing contractures}

Divergent perceptions emerged regarding difficulties in everyday life; what degree of contracture and which joint had affected the participants' hand function the most. For the MCP joint, problems were considered to arise from extension deficits from 25 to 60 degrees, the most common estimate being 40 to 45 degrees. In the PIP joint 30 degrees was considered disturbing and 55 degrees very troublesome. Having both MCP and PIP joints affected, even less than 30 degrees, was more disturbing than having the equivalent contracture in only one joint. The ability to hyperextend the MCP joint made a PIP joint contracture more easily tolerated. 


\section{DISCUSSION}

The present study showed significantly improved ROM after $\mathrm{CCH}$ treatment, although extension deficits gradually deteriorated over time. Five years after treatment, the total extension deficit averaged $48^{\circ}$, which is $57 \%$ of the deficit before treatment. Of the selfreported hand function aspects, stiffness caused most problems both before and five years after treatment, while pain, problems with pressure/touch to the palm and cold sensitivity decreased over time. QuickDASH scores and overall satisfaction with treatment were best at three months after treatment and then deteriorated slightly over time. However, disability was still significantly lower compared to before treatment and most patients were satisfied with their hand function and ability to use the hand in daily activities five years after treatment. The clinical experience of the $\mathrm{CCH}$ treatment observed in the present study was that some oedema and pain decreased before the extension manipulation was performed, which differs from previous studies (Gaston et al., 2015; Hurst et al., 2009). In several cases, the cord had partially ruptured before the patients' return visit to the physician. A lower residual contracture before manipulation has been described previously (Mickelson et al., 2014). Another choice regarding treatment in the present study was not to withhold anticoagulant medication before $\mathrm{CCH}$ treatment, which differs from recommendations by Hurst at al. (2009). The regimen was initially chosen for a patient who was at serious risk if the anticoagulant treatment was discontinued. The patient was be able to complete the $\mathrm{CCH}$ treatment without any problems, and therefore this protocol was implemented.

Most studies about Dupuytren's disease report passive extension measures (Hurst et al., 2009; Kaplan and Crosby, 2018; van Rijssen et al., 2012; Strömberg et al., 2018), while it is unclear in others if active or passive extension is measured (Gaston et al., 2015; Peimer et al., 2015a), which may affect the result (Pratt and Ball, 2016; Rodrigues et al., 2015). In the present study active extension was measured as recommended in the Swedish national quality register of 
hand surgery because it correlates better with hand function and patients experience of extension deficit (Rodrigues et al., 2015).

Patients often perceive $\mathrm{CCH}$ treatment as a simple procedure compared to fasciectomy due to the rapid healing process (Hurst et al., 2009; Leclère et al., 2018). In general, the participants reported few hand function problems in the present study. However, oedema and pain occurred from the $\mathrm{CCH}$ injection which has also been described previously (Nordenskjöld et al., 2017; Peimer et al., 2015b; Sanjuan-Cervero et al., 2017). CCH injection appears not to cause reduced touch sensation although some participants reported new or increased cold sensitivity in treated fingers at the final follow-up without having trauma or other explanation. Reasons for developing cold sensitivity after treatment for Dupuytren's disease are still unknown (King and Belcher, 2014; Mckirdy et al., 2007; Namazi and Majd, 2014). Overall, $\mathrm{CCH}$ treatment seems to be well suited also for older people resulting in improved hand function.

Although satisfaction with treatment declined after decreasing finger extension, the majority in the present study were still pleased, which is consistent with previous findings (Bradley and Warwick, 2016; Leclère et al., 2018). At five-year follow-up satisfaction with hand function and ability to use the hand was, in general, high which may reflect that most participants had an improved functional ROM. Participants in the present study had varying opinions about troublesome joint deficits with lower thresholds for reduced mobility in daily activities compared to a previous study by Raymond et al. (2015). However, the angles leading to dysfunctional contractures estimated by patients in the present study were similar to the inclusion criteria for treatment at our hospital.

There are limitations of the present study due to the retrospective study design and the small and heterogeneous sample. Extension deficit in a single PIP joint can affect hand function differently than an equivalent extension deficit distributed among all finger joints. Similarly, 
treatment of contractures in MCP joints may have better results than contractures in PIP joints. The series did not have sufficient power for subgroup analysis of this. However, the sample is well represented for Dupuytren's disease patients in terms of gender, age, heredity, diabetes, bi-/ unilateral disease, etc. Another limitation of the present study is that we cannot compare our outcomes to previous definitions of recurrence, such as by Kan et al. (2017), due to not measuring passive movement. However, the focus of the present study was on hand function and not primarily on recurrence rates.

The same physician treated all the patients, which led to consistent routines in the implementation. Close cooperation existed with OTs responsible for rehabilitation after the $\mathrm{CCH}$ injection which enabled structured follow-up and documentation of data. The findings of this long-term follow-up may be of interest for clinicians treating patients with Dupuytren's disease.

It can be concluded that hand function was significantly improved although the contractures deteriorated over time. Most patients (70\%) gained more than the functional ROM needed for performance of common daily activities. Treatment with $\mathrm{CCH}$ injection was a valued method that many patients would choose again. 


\section{REFERENCES}

Altman DG, Bland JM. Statistics notes. Units of analysis. BMJ. 1997, 314: 1874.

Atroshi I, Gummesson C, Andersson B, Dahlgren E, Johansson A. The disabilities of the arm, shoulder and hand (DASH) outcome questionnaire: reliability and validity of the Swedish version evaluated in 176 patients. Acta Orthop Scand. 2000, 71: 613-8.

Bain GI, Polites N, Higgs BG, Hepinstall RJ, McGrath AM. The functional range of motion of the finger joints. J Hand Surg Eur. 2015, 40: 406-11.

Ball C, Pratt AL, Nanchahal J. Optimal functional outcome measures for assessing treatment for Dupuytren's disease: a systematic review and recommendations for future practice. BMC Muskuloskelet Disord. 2013, 14: 131.

Bell Krotoski J. Sensibility testing. In: Skirven T, Osterman L, Fedorczyk J, Amadio P. (Eds.) Rehabilitation of the hand and upper extremity. 6th ed. Philadelphia: Elsevier/Mosby, 2011, Vol. 1: 132-51.

Bradley J, Warwick D. Patient satisfaction with collagenase. J Hand Surg Am. 2016, 41: 68997.

Bryant D, Havey TC, Roberts R, Guyatt G. How many patients? How many limbs? Analysis of patients or limbs in the orthopedic literature, a systematic review. J Bone Joint Surg Am. 2006, 88: 41-5. 
Franchignoni F, Vercelli S, Giordano A, Sartorio F, Bravini E, Ferriero G. Minimal clinically important difference of the Disabilities of the Arm, shoulder and Hand outcome measure (DASH) and its shortened version (QuickDASH). J Orthop Sports Phys Ther. 2014, 44: 30-9.

Gaston RG, Larsen SE, Pess GM et al. The efficacy and safety of concurrent Collagenase Clostridium Histolyticum injections for 2 Dupuytren contractures in the same hand: A prospective, multicenter study. J Hand Surg Am. 2015, 40: 1963-71.

HAKIR. HQ-8-english questionnaire postoperative (2018). Translated from Swedish version (2010). https://hakir.se/wp-content/uploads/2018/11/HQ-8-questionnaire-English-181003-.pdf (Retrieved 2020 May 4).

HAKIR. National manual for measuring motion and strength in the elbow, forearm and hand (2019). Translated from Swedish version (2010). https://hakir.se/wpcontent/uploads/2019/03/Manual-for-rorelse-styrka-Version-1-2016 Eng.pdf (Retrieved 2020 May 4).

Hurst L, Badalamente M, Hentz V et al. Injectable collagenase clostridium histolyticum for Dupuytren's contracture. N Engl J Med. 2009, 361: 968-79.

Kan HJ, de Bekker-Grob EW, van Marion ES et al. Patients' preferences for treatment for Dupuytren's disease: a discrete choice experiment. Plast Reconstr Surg. 2016, 137: 165-73. 
Kan HJ, Verrijp FW, Hovius SE, van Nieuwenhoven CA, Dupuytren Delphi Group, Selles RW. Recurrence of Dupuytren's contracture: a consensus-based definition. PLoS ONE. 2017, 12: e0164849.

Kaplan FTD, Crosby N. Treatment of recurrent Dupuytren disease. Hand Clin. 2018, 34: 403-15.

King IC, Belcher HJ. Cold intolerance following collagenase clostridium histolyticum treatment for Dupuytren Contracture. J Hand Surg Am. 2014, 39: 808-9.

Layton T, Nanchahal J. Recent advances in the understanding of Dupuytren's disease. F1000Res. 2019, 8, F1000 Faculty rev 231. https://doi.org/10.12688/f1000research.17779.1.

Leclère FM, Kohl S, Varonier C, Unglaub F, Vögelin E. Range of motion, postoperative rehabilitation and patient satisfaction in MCP and PIP joints affected by Dupuytren Tubiana stage 1 - 3: collagenase enzymatic fasciotomy or limited fasciectomy? A clinical study in 52 patients. Arch Orthop Trauma Surg. 2018, 138: 1623-31.

Matthews JN, Altman DG, Campbell MJ, Royston P. Analysis of serial measurements in medical research. BMJ. 1990, 300: 230-5.

Mckirdy S, Jacobs N, Nassab R, Starley I. Retrospective review of cold intolerance following corrective surgery for Dupuytren's disease. Br J Hand Ther. 2007, 12: 55-9. 
Mickelson DT, Noland SS, Watt AJ, Kollitz KM, Vedder NB, Huang JI. Prospective randomized controlled trial comparing 1- versus 7-day manipulation following collagenase injection for Dupuytren contracture. J Hand Surg Am. 2014, 39: 1933-41.

Namazi H, Majd Z. Cold intolerance following collagenase Clostridium histolyticum treatment for Dupuytren contracture: A molecular mechanism. J Hand Surg Am. 2014, 39: $1886-7$

Nordenskjöld J, Lauritzson A, Åkesson A, Atroshi I. Collagenase injections for Dupuytren disease: 3-year treatment outcomes and predictors of recurrence in 89 hands. Acta Orthop. 2019, 90: 517-22.

Nordenskjöld J, Waldén M, Kjellin A, Franzén H, Atroshi I. Benefit of local anesthesia in reducing pain during collagenase injection for Dupuytren's contracture. Plast Reconstr Surg. 2017, 140: 565-9.

Peimer CA, Blazar P, Coleman S, Kaplan FT, Smith T, Lindau T. Dupuytren contracture recurrence following treatment with Collagenase Clostridium histolyticum (CORDLESS [Collagenase option for reduction of Dupuytren long-term evaluation of safety study]): 5year data. J Hand Surg Am. 2015, 40: 1597-605.

Peimer CA, Wilbrand S, Gerber RA, Chapman D, Szczypa PP. Safety and tolerability of collagenase Clostridium histolyticum and fasciectomy for Dupuytren's contracture. J Hand Surg Eur. 2015, 40: 141-9. 
Pratt AL, Ball C. What are we measuring? A critique of range of motion methods currently in use for Dupuytren's disease and recommendations for practice. BMC Musculoskelet Disord. 2016, 17: 20.

Raymond A, Parry M, Amirfeyz R. Critical angles of deformity in Dupuytren's contracture of the little and ring fingers. Hand Surg. 2015, 20: 290-7.

Rodrigues JN, Zhang W, Scammell BE, Davis TRC. Dynamism in Dupuytren`s contractures. J Hand Surg Eur. 2015, 40: 166-70.

Rodrigues JN, Zhang W, Scammell BE et al. Validity of the Disabilities of the Arm, Shoulder and Hand patient reported outcome measure (DASH) and the QuickDASH when used in Dupuytren's disease. J Hand Surg Eur. 2016, 41: 589-99.

Sanjuan-Cervero R, Carrera-Hueso F, Vazquez-Ferreiro P, Gomez-Herrero D. Adverse effects of collagenase in the treatment of Dupuytren disease: A systematic review. BioDrugs. 2017, 31: 105-15.

Strömberg J, Sörensen AI, Fridén J. Percutaneus needle fasciotomy versus collagenase treatment for Dupuytren contracture. A randomized controlled trial with a two-year followup. J Bone Joint Surg Am. 2018, 100: 1079-86.

Tang JB, Giddins G. Why and how to report surgeons' levels of expertise. J Hand Surg Eur. 2016, 41: 365-6. 
Van Rijssen AL, ter Linden H, Werker PM. Five-year results of a randomized clinical trial on treatment in Dupuytren's disease: percutaneous needle fasciotomy versus limited fasciectomy. Plast Reconstr Surg. 2012, 129: 469-77.

Werlinrud J, Hansen K, Larsen S, Lauritsen J. Five-year results after collagenase treatment of Dupuytren disease. J Hand Surg Eur. 2019, 43: 841-7.

Zhao J, Hadley S, Floyd E, Earp B, Blazar P. The impact of Collagenase Clostridium histolyticum. Introduction on Dupuytren treatment patterns in the United States. J Hand Surg Am. 2016, 41: 963-8. 


\section{Figure legends}

Figure 1. Extension deficit in individual joints and the entire finger, presented per subgroup, before $\mathrm{CCH}$ treatment and at three months, twelve months, and five year follow-up. One finger $=$ whole line, two or three fingers $=$ hatched line

$\mathrm{x}=$ significant difference from baseline, $p<0.001$

$\mathrm{Q}=$ significant difference both from baseline and from previous assessments, $p<0.001$ 
Table S1. Change over time in: A. Total active extension deficit and for isolated joints; B. Finger flexion; and $\mathrm{C}$. Total active range of motion (AROM).

\begin{tabular}{|c|c|c|c|c|c|}
\hline & $\mathrm{n}$ & Baseline & 3 months & 12 months & 5 years \\
\hline \multicolumn{6}{|l|}{ A. Extension deficit } \\
\hline Total active extension deficit & 79 & $84(27)$ & $20(16)$ & $26(19)$ & $48(39)$ \\
\hline Treated in 1 finger & 56 & $87(27)$ & $19(15)$ & $25(18)$ & $48(39)$ \\
\hline Treated in 2-3 fingers & 23 & $76(28)$ & $21(18)$ & $28(21)$ & $50(40)$ \\
\hline $\begin{array}{l}\mathrm{CCH} \text { injection as primary } \\
\text { treatment }\end{array}$ & 53 & $84(28)$ & 17 /14) & $22(19)$ & $44(41)$ \\
\hline $\begin{array}{l}\text { Previous fasciectomy in same } \\
\text { finger }\end{array}$ & 11 & $93(28)$ & $31(17)$ & $35(20)$ & $66(32)$ \\
\hline MCP-joint extension deficit & & $46(20)$ & $6(8)$ & $7(10)$ & $17(21)$ \\
\hline Treated in 1 finger & 56 & $48(22)$ & $5(8)$ & $6(8)$ & $16(21)$ \\
\hline Treated in 2-3 fingers & 23 & $42(16)$ & 7 (9) & $12(12)$ & $21(21)$ \\
\hline $\begin{array}{l}\mathrm{CCH} \text { injection as primary } \\
\text { treatment }\end{array}$ & 53 & $48(19)$ & $5(8)$ & $7(9)$ & $15(21)$ \\
\hline $\begin{array}{l}\text { Previous fasciectomy in same } \\
\text { finger }\end{array}$ & 11 & $39(23)$ & $3(4)$ & $8(10)$ & $26(25)$ \\
\hline PIP-joint extension deficit & & $34(24)$ & $13(14)$ & $17(16)$ & $28(24)$ \\
\hline Treated in 1 finger & 56 & $37(26)$ & $14(14)$ & $18(17)$ & $30(25)$ \\
\hline Treated in 2-3 fingers & 23 & $29(20)$ & $12(12)$ & $14(14)$ & $23(21)$ \\
\hline $\begin{array}{l}\mathrm{CCH} \text { injection as primary } \\
\text { treatment }\end{array}$ & 53 & $33(26)$ & $11(12)$ & $14(16)$ & $26(25)$ \\
\hline $\begin{array}{l}\text { Previous fasciectomy in same } \\
\text { finger }\end{array}$ & 11 & $42(19)$ & $24(14)$ & $23(15)$ & $35(17)$ \\
\hline DIP-joint extension deficit & & $3(8)$ & $1(3)$ & $2(5)$ & $3(7)$ \\
\hline Treated in 1 finger & 56 & $3(7)$ & $1(2)$ & $2(5)$ & $3(7)$ \\
\hline Treated in 2-3 fingers & 23 & $5(8)$ & $2(5)$ & $2(5)$ & $5(7)$ \\
\hline $\begin{array}{l}\mathrm{CCH} \text { injection as primary } \\
\text { treatment }\end{array}$ & 53 & $3(6)$ & $2(15)$ & $1(4)$ & $3(7)$ \\
\hline $\begin{array}{l}\text { Previous fasciectomy in same } \\
\text { finger }\end{array}$ & 11 & $11(14)$ & $4(7)$ & $4(7)$ & $6(8)$ \\
\hline \multicolumn{6}{|l|}{ B. Flexion } \\
\hline Total active flexion & 79 & $237(19)$ & $242(20)$ & 242 (19) & $241(21)$ \\
\hline Treated in 1 finger & 56 & $234(19)$ & $239(21)$ & 240 (19) & $239(23)$ \\
\hline Treated in 2-3 fingers & 23 & $245(16)$ & $250(18)$ & $248(17)$ & $245(16)$ \\
\hline MCP-joint flexion & & $88(7)$ & $88(7)$ & $88(7)$ & $87(9)$ \\
\hline Treated in 1 finger & 56 & $88(8)$ & $88(7)$ & $88(7)$ & $87(9)$ \\
\hline Treated in 2-3 fingers & 23 & $87(6)$ & $87(6)$ & $87(6)$ & $87(8)$ \\
\hline PIP-joint flexion & & $94(9)$ & $95(10)$ & $95(9)$ & $96(10)$ \\
\hline Treated in 1 finger & 56 & $93(10)$ & $93(11)$ & $94(10)$ & $96(11)$ \\
\hline Treated in 2-3 fingers & 23 & $96(7)$ & $99(5)$ & $97(5)$ & $97(7)$ \\
\hline DIP-joint flexion & & $56(15)$ & $60(16)$ & $60(16)$ & $57(17)$ \\
\hline Treated in 1 finger & 56 & $53(16)$ & $58(17)$ & $58(17)$ & $56(19)$ \\
\hline Treated in 2-3 fingers & 23 & $62(12)$ & $65(13)$ & $64(14)$ & $61(12)$ \\
\hline
\end{tabular}




\begin{tabular}{|c|c|c|c|c|c|}
\hline \multicolumn{6}{|l|}{ C. Total active range of motion } \\
\hline Total AROM & 79 & $154(35)$ & $223(29)$ & $217(30)$ & $193(44)$ \\
\hline Treated in 1 finger & 56 & $147(33)$ & $220(29)$ & $216(30)$ & $192(45)$ \\
\hline Treated in 2-3 fingers & 23 & $170(36)$ & $229(28)$ & $220(30)$ & $195(44)$ \\
\hline $\begin{array}{l}\mathrm{CCH} \text { injection as primary } \\
\text { treatment }\end{array}$ & 53 & $154(34)$ & $226(27)$ & $221(28)$ & $200(44)$ \\
\hline $\begin{array}{l}\text { Previous fasciectomy in same } \\
\text { finger }\end{array}$ & 11 & $143(35)$ & $207(41)$ & $205(35)$ & $170(35)$ \\
\hline MCP-joint AROM & & $42(20)$ & $82(11)$ & $80(13)$ & $70(23)$ \\
\hline Treated in 1 finger & 56 & $40(21)$ & $84(11)$ & $83(12)$ & $72(23)$ \\
\hline Treated in 2-3 fingers & 23 & $46(17)$ & $79(12)$ & $75(14)$ & $66(22)$ \\
\hline $\begin{array}{l}\mathrm{CCH} \text { injection as primary } \\
\text { treatment }\end{array}$ & 53 & $39(18)$ & $82(10)$ & $81(12)$ & $73(21)$ \\
\hline $\begin{array}{l}\text { Previous fasciectomy in same } \\
\text { finger }\end{array}$ & 11 & $53(23)$ & $88(10)$ & $84(15)$ & $67(28)$ \\
\hline PIP-joint AROM & & $59(24)$ & $82(17)$ & 78 (19) & $69(25)$ \\
\hline Treated in 1 finger & 56 & $56(25)$ & $79(17)$ & $77(20)$ & $67(26)$ \\
\hline Treated in 2-3 fingers & 23 & $67(21)$ & $87(13)$ & $83(15)$ & $74(23)$ \\
\hline $\begin{array}{l}\mathrm{CCH} \text { injection as primary } \\
\text { treatment }\end{array}$ & 53 & $61(25)$ & $84(15)$ & $81(17)$ & $71(26)$ \\
\hline $\begin{array}{l}\text { Previous fasciectomy in same } \\
\text { finger }\end{array}$ & 11 & $47(21)$ & $66(22)$ & $67(21)$ & $56(20)$ \\
\hline DIP-joint AROM & & $52(16)$ & $59(16)$ & $58(17)$ & $54(17)$ \\
\hline Treated in 1 finger & 56 & $51(16)$ & $57(17)$ & $57(18)$ & $53(18)$ \\
\hline Treated in 2-3 fingers & 23 & $57(13)$ & $63(15)$ & $62(15)$ & $56(13)$ \\
\hline $\begin{array}{l}\mathrm{CCH} \text { injection as primary } \\
\text { treatment }\end{array}$ & 53 & $54(13)$ & $60(14)$ & $59(15)$ & $57(14)$ \\
\hline $\begin{array}{l}\text { Previous fasciectomy in same } \\
\text { finger }\end{array}$ & 11 & $43(24)$ & $50(27)$ & $54(25)$ & $47(23)$ \\
\hline
\end{tabular}

Data presented as mean (SD) degrees for the whole group, subgroups, patients with $\mathrm{CCH}$ injection as primary treatment and patients previous treated in same finger. ${ }^{*}$ The difference between total active flexion and total active extension in MCP, PIP and DIP joints. 
Table S2. Satisfaction with hand function and ability to use hand in daily activities related to degree of total active extension (TAE) deficit in worst finger at the five-year follow-up and to age $(n=79)$.

\begin{tabular}{|c|c|c|c|}
\hline \multirow[t]{2}{*}{ secting } & \multicolumn{2}{|r|}{$\begin{array}{c}\text { Satisfaction with hand } \\
\text { function }\end{array}$} & \multirow{2}{*}{$\begin{array}{c}\text { Ability to use the hand } \\
\text { Fairly good, good, very } \\
\text { good, } \\
\text { Yes (\%) }\end{array}$} \\
\hline & $\mathrm{n}$ & High or very high, Yes (\%) & \\
\hline \multicolumn{4}{|l|}{ Degree of extension deficit } \\
\hline $\begin{array}{l}\text { TAE deficit } \leq 45^{\circ} \text { in worst } \\
\text { finger }\end{array}$ & 45 & $37(82)$ & $42(93)$ \\
\hline $\begin{array}{l}\text { TAE deficit }>45^{\circ} \text { in worst } \\
\text { finger }\end{array}$ & 34 & $9(26)$ & $21(62)$ \\
\hline Treated in 1 finger & 56 & & \\
\hline TAE deficit $\leq 45^{\circ}$ & 33 & $30(91)$ & $31(94)$ \\
\hline TAE deficit $>45^{\circ}$ & 23 & $4(17)$ & $13(57)$ \\
\hline Treated in 2 or 3 fingers & 23 & & \\
\hline TAE deficit $\leq 45^{\circ}$ & 12 & $7(58)$ & $11(92)$ \\
\hline TAE deficit $>45^{\circ}$ & 11 & $5(45)$ & $8(73)$ \\
\hline \multicolumn{4}{|l|}{ Age (at injection) } \\
\hline The whole group & 79 & & \\
\hline$\leq 68$ years & 41 & $21(51)$ & $31(76)$ \\
\hline$>68$ & 38 & $25(66)$ & $32(84)$ \\
\hline Treated in 1 finger & 56 & & \\
\hline$\leq 68$ years & 30 & $17(57)$ & $23(77)$ \\
\hline$>68$ & 26 & $17(65)$ & $21(81)$ \\
\hline Treated in 2 or 3 fingers & 23 & & \\
\hline$\leq 68$ years & 11 & $4(36)$ & $8(73)$ \\
\hline$>68$ & 12 & $8(67)$ & $11(92)$ \\
\hline
\end{tabular}

Data is presented as number of patients (\%). 
Table1. Patient reported background data and interventions for study sample at 5 years.

\begin{tabular}{|c|c|c|c|c|c|}
\hline & & $\begin{array}{c}\text { All } \\
\text { patients } \\
\mathrm{n}=79\end{array}$ & $\begin{array}{l}\text { Patients } \\
\text { treated in } \\
1 \text { finger } \\
n=56\end{array}$ & $\begin{array}{c}\text { Patients } \\
\text { treated in } \\
2 \text { or } 3 \\
\text { fingers } \\
n=23\end{array}$ & $\begin{array}{c}\text { Difference } \\
\text { between } \\
\text { Groups } \\
p \text {-values }\end{array}$ \\
\hline \multicolumn{6}{|l|}{ Background data } \\
\hline Sex & Male (\%) & $68(86)$ & $49(88)$ & $19(82)$ & 0,722 \\
\hline Age at injection & Mean (SD) & $68(9)$ & $67(8)$ & $70(11)$ & 0,321 \\
\hline Working & & $13(16)$ & $11(20)$ & $2(9)$ & 0,326 \\
\hline Smoking & & $7(8)$ & $5(9)$ & $2(9)$ & 1,000 \\
\hline Diabetes & & $13(16)$ & $9(16)$ & $4(17)$ & 1,000 \\
\hline \multirow[t]{2}{*}{ DD in family } & Yes & $48(61)$ & $33(59)$ & $15(65)$ & 0,758 \\
\hline & Uncertain & $14(18)$ & $10(18)$ & $4(17)$ & \\
\hline \multirow[t]{4}{*}{ Disease duration } & $0-5 y$ & $9(11)$ & $8(14)$ & $1(4)$ & \\
\hline & $6-10 y$ & $26(33)$ & $18(32)$ & $8(35)$ & \\
\hline & $11-15 y$ & $18(23)$ & $13(23)$ & $5(22)$ & \\
\hline & $>15 y$ & $26(33)$ & $17(30)$ & 9 (39) & \\
\hline Bilateral disease & & $60(76)$ & $40(71)$ & $20(87)$ & 0,245 \\
\hline \multicolumn{6}{|c|}{ Previous treatment with fasciectomy (before injection) } \\
\hline In the same hand as injection & & $11(14)$ & $6(11)$ & $5(22)$ & 0,282 \\
\hline Treated once & & $6(8)$ & $5(9)$ & $1(4)$ & 0,666 \\
\hline Treated twice & & $1(0)$ & $0(0)$ & $1(4)$ & 0,291 \\
\hline Treated $>$ two times & & $5(6)$ & $1(1)$ & $4(17)$ & 0,024 \\
\hline None & & $53(67)$ & $41(73)$ & $12(52)$ & 0,112 \\
\hline Treated only in the other hand & & $15(19)$ & $9(16)$ & $6(26)$ & 0,350 \\
\hline Treated in both hands & & $9(11)$ & $4(7)$ & $5(22)$ & 0,112 \\
\hline \multicolumn{6}{|l|}{ Intervention given at baseline } \\
\hline Patients treated in one finger & & & $56(70)$ & & - \\
\hline Patients treated in two fingers & & & & $20(25)$ & - \\
\hline Patients treated in three fingers & & & & $3(4)$ & - \\
\hline Patients treated in index finger & & $0(0)$ & $0(0)$ & $0(0)$ & - \\
\hline Patients treated in long finger & & $13(16)$ & $3(5)$ & $10(43)$ & - \\
\hline Patients treated in ring finger & & $38(48)$ & $16(29)$ & $22(96)$ & - \\
\hline Patients treated in little finger & & $54(68)$ & $37(66)$ & $17(74)$ & - \\
\hline Treated in dominant hand & & $45(57)$ & $33(59)$ & $12(52)$ & - \\
\hline Complications & & $n=79$ & & & \\
\hline Skin rupture & & $32(41)$ & $20(36)$ & $12(52)$ & 0,212 \\
\hline
\end{tabular}

Repeated interventions given to the same hand and fingers after the first Xiapex injection until 5 years followup*

$\begin{array}{lcccc} & n=73 & n=52 & n=21 & \\ \begin{array}{l}\text { No further intervention after } \\ \text { baseline }\end{array} & 62(78) & 47(84) & 15(65) & 0,078\end{array}$


Xiapex injection

$7(8) \quad 4(7)^{*}$

$3(13)$

Fasciectomy

$4(5) \quad 1(2)$

$3(13)^{*}$

Data presented as number (\%); *Two patients underwent repeated interventions with $\mathrm{CCH}$ injection and fasciectomy respectively. 
Table 2. Active range of motion (AROM) for the whole finger and for isolated joints compared to functional range of motion at baseline and at 5 -years follow up. Patients who had further treatment excluded, $\mathrm{n}=70$.

\begin{tabular}{|c|c|c|c|c|c|c|}
\hline & $\begin{array}{c}\text { Baseline } \\
\text { AROM } \\
\text { (degrees) }\end{array}$ & $\begin{array}{c}\text { Functional } \\
\text { ROM* } \\
\text { (degrees) }\end{array}$ & $\begin{array}{c}\text { Patients } \\
\text { exceeding } \\
\text { Functional } \\
\text { ROM at } \\
\text { baseline } \\
\end{array}$ & $\begin{array}{c}5 \text { years } \\
\text { AROM } \\
\text { (degrees) }\end{array}$ & $\begin{array}{c}\text { Patients } \\
\text { surpassing } \\
\text { Functional } \\
\text { ROM at } 5 \\
\text { years } \\
\end{array}$ & $\begin{array}{c}p \text {-values of } \\
\text { change from } \\
\text { baseline to } \\
5 \text {-year } \\
\text { follow up }\end{array}$ \\
\hline Whole finger & $154(35)$ & 170 & 27 (39) & 193(44) & $49(70)$ & 0.001 \\
\hline MCP-joints & $4220)$ & 52 & $17(24)$ & $70(23)$ & $53(76)$ & $<0.001$ \\
\hline PIP-joints & $59(24)$ & 64 & $35(50)$ & $69(25)$ & $43(61)$ & 0.153 \\
\hline DIP-joints & $52(16)$ & 54 & $39(56)$ & $54(17)$ & $42(60)$ & 0.479 \\
\hline
\end{tabular}

Data presented as mean (SD) or number of patients (\%); * The range of motion needed to perform activities of daily living according to Bain at al. (2015). 
Table 3. Patients rating of hand function problems, sensibility testing and Quick-DASH at the follow-up assessments ( $n=79)$.

\begin{tabular}{|c|c|c|c|c|}
\hline & $\begin{array}{c}\text { Pre } \\
\text { treatment }\end{array}$ & 3 months & 12 months & 5 years \\
\hline \multicolumn{5}{|l|}{ Pain (Median (Q1-Q3)) } \\
\hline at rest* & $4(2-13)$ & $3(1-5)$ & $3(2-6)$ & $0(0-0)$ \\
\hline on motion without load* & $4(2-10)$ & $2(1-5)$ & $3(2-7)$ & $0(0-0)$ \\
\hline on load* & $11(2-30)$ & $3(1-9)$ & $3(2-13)$ & $0(0-10)$ \\
\hline at injection/ pain in hand, yes (\%) & $51(65)$ & $11(14)$ & $12(15)$ & $7(9)$ \\
\hline Stiffness*, median (Q1-Q3) & $65(48-90)$ & $9(2-22)$ & $5(3-31)$ & $20(0-40)$ \\
\hline Weakness*, median (Q1-Q3) & $27(5-48)$ & $3(2-12)$ & $5(2-16)$ & $0(0-20)$ \\
\hline \multicolumn{5}{|l|}{ Numbness/tingling in fingers*, median } \\
\hline (Q1-Q3) & $6(2-35)$ & $3(2-12)$ & $4(2-10)$ & $0(0-10)$ \\
\hline Cold sensitivity*, median (Q1-Q3) & $22(3-70)$ & $4(2-41)$ & $5(2-36)$ & $0(0-40)$ \\
\hline VAS >50/100, n (\%) & $30(38)$ & $11(14)$ & $13(16)$ & $13(16)$ \\
\hline \multicolumn{5}{|l|}{$\begin{array}{l}\text { Sensibility during the first year after } \\
\text { treatment }^{\mathrm{a}}\end{array}$} \\
\hline $\begin{array}{l}\text { Decreased or no protective sensibility in } \\
\text { worst finger, } \mathrm{n}(\%)\end{array}$ & $16(20)$ & $9(11)$ & $11(14)$ & \\
\hline \multicolumn{5}{|l|}{$\begin{array}{l}\text { Discomfort from touch and } \\
\text { pressure to the palm after treatment, } n(\%)\end{array}$} \\
\hline No discomfort & & $69(88)$ & $63(80)$ & $71(90)$ \\
\hline Light discomfort & & $8(10)$ & $5(6)$ & $3(4)$ \\
\hline Moderate discomfort & & $1(1)$ & $5(6)$ & $5(6)$ \\
\hline Missing & & 1 & 6 & 0 \\
\hline \multicolumn{5}{|l|}{ Quick-DASH, mean (SD) } \\
\hline All patients & $24(15)$ & $7(11)$ & $10(13)$ & $12(12)$ \\
\hline Treated in 1 finger & $21(15)$ & $7(10)$ & $8(11)$ & $11(13)$ \\
\hline Treated in 2 or 3 fingers & $31(13)$ & $9(13)$ & $15(16)$ & $14(12)$ \\
\hline \multicolumn{5}{|c|}{ 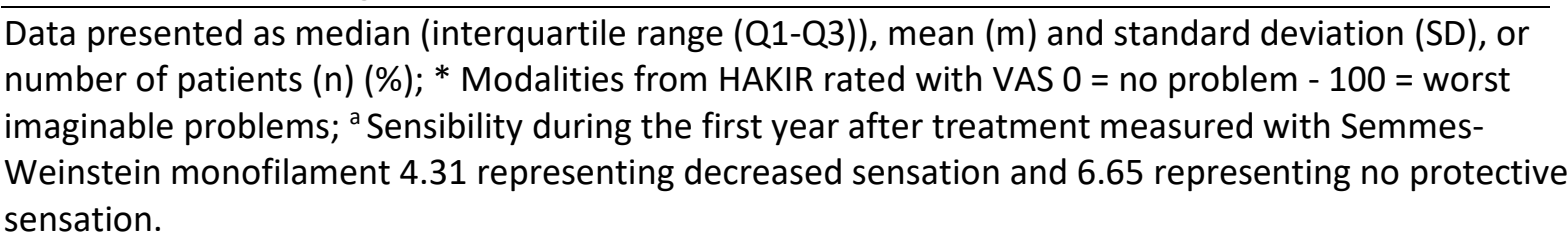 } \\
\hline
\end{tabular}


Table 4. Patients self-reported satisfaction with hand function and ability to use hand in daily activities at 5 -year follow up presented based on subgroups of number of treated fingers and treatment history $(n=79)$.

\begin{tabular}{|c|c|c|c|c|c|c|c|c|}
\hline \multirow[b]{2}{*}{$\begin{array}{l}\text { Satisfaction with hand function, } \\
\text { rated as high or very high }\end{array}$} & \multicolumn{2}{|c|}{$\begin{array}{l}\text { All patients, } \\
\text { regardless of } \\
\text { treatment } \\
\text { history }\end{array}$} & \multicolumn{2}{|c|}{$\begin{array}{l}\text { No previous } \\
\text { treatment }^{\text {a }}\end{array}$} & \multicolumn{2}{|c|}{$\begin{array}{c}\text { Previous } \\
\text { treatment }^{b *}\end{array}$} & \multicolumn{2}{|c|}{$\begin{array}{c}\text { New } \\
\text { treatment }\end{array}$} \\
\hline & $\mathrm{n}$ & & $\mathrm{n}$ & & $\mathrm{n}$ & & $\mathrm{n}$ & \\
\hline The whole group & 79 & $46(58)$ & 42 & $30(71)$ & 26 & $10(38)$ & 17 & $7(41)$ \\
\hline Treated in 1 finger & 56 & $34(61)$ & 34 & $25(74)$ & 15 & $5(33)$ & 10 & $4(40)$ \\
\hline Treated in 2-3 fingers & 23 & $12(52)$ & 8 & $5(63)$ & 11 & $5(45)$ & 7 & $3(43)$ \\
\hline $\begin{array}{l}\text { Ability to use the hand in daily } \\
\text { activities, rated as fairly good, } \\
\text { good or very good }{ }^{d}\end{array}$ & $n$ & & $\mathrm{n}$ & & $\mathrm{n}$ & & $\mathrm{n}$ & \\
\hline The whole group & 79 & $63(80)$ & 42 & $35(83)$ & 26 & $19(73)$ & 17 & $13(76)$ \\
\hline Treated in 1 finger & 56 & $44(79)$ & 34 & $30(88)$ & 15 & $8(53)$ & 10 & $7(70)$ \\
\hline Treated in 2-3 fingers & 23 & $19(83)$ & 8 & $5(63)$ & 11 & $11(100)$ & 7 & $6(86)$ \\
\hline \multicolumn{9}{|c|}{$\begin{array}{l}\text { Data is presented as number (percentage); } \\
\text { * Including patients treated both before and after the first } \mathrm{CCH} \text { injection; } \\
\text { a Patients never treated for Dupuytren's disease before or after the } \mathrm{CCH} \text { injection; }\end{array}$} \\
\hline \multicolumn{9}{|c|}{$\begin{array}{l}\text { b Patients treated for Dupuytren's disease with other methods in either hand before the } \mathrm{CCH} \\
\text { injection; } \\
\text { c Patients treated in either hand for recurrent Dupuytren's disease after the } \mathrm{CCH} \text { injection; } \\
\text { d Rating 8-10 on a ten-point scale ranging from 1=very poor, 10=very good. }\end{array}$} \\
\hline
\end{tabular}




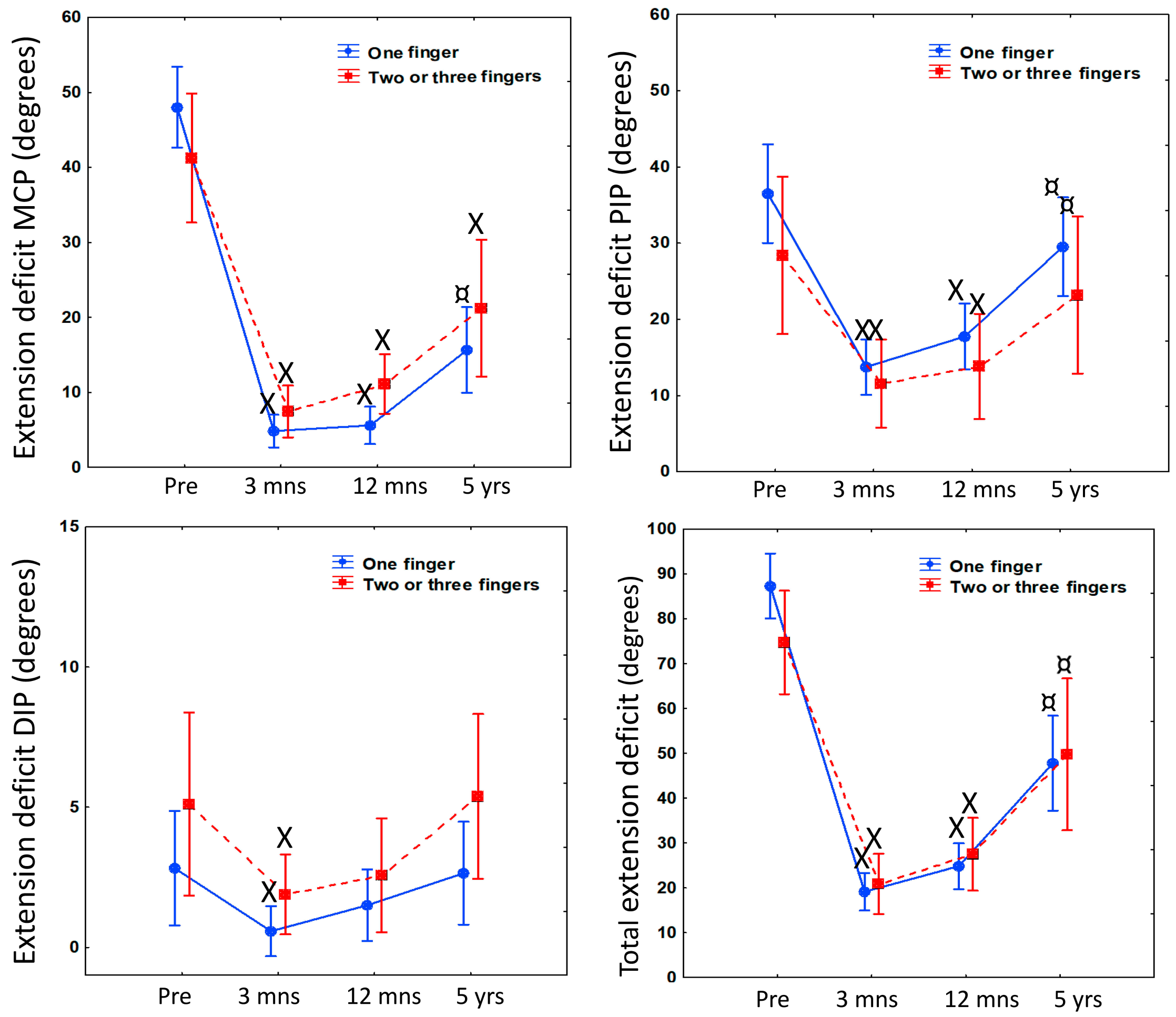